\title{
Leadership and Management as an Enabler for Strategy Execution in Municipalities in South Africa
}

\author{
JH Leibbrandt Dr \\ North-West University, Potchefstroom, South Africa 2520 \\ Email: leibbrandt.johan@ke.pwc.com
}

CJ Botha Prof

Associate Professor, North-West University, Potchefstroom, South Africa 2520

Email: Christoff.botha@nwu.ac.za

Doi:10.5901/mjss.2014.v5n20p329

\section{Abstract}

Research and literature confirmed that whilst progress has been made in recent years, there is still a pressing need amongst communities in South Africa for improved service delivery. There is also increasing frustration and anger at the inability of municipalities to do what is expected of them. Municipalities in general have a poor record in respect of execution of strategy. The paper will focus in the literature review on the 8 'S' strategy execution framework developed by Higgins (2005), that is based on the McKinsey Seven 'S' s Framework, first introduced in 1980 by Thomas J. Peters and Robert H. Waterman, Jr. It is clearly indicting that an excellent strategy may put a municipality or business on the competitive map but only successful execution will keep it there. Research and literature to date focused primarily on planning and strategy formulation but neglected the very important execution process. Whilst strategy execution is a dismal failure in most organizations, very little research to date focused on strategy execution. Managers and their employees must apply new ways of thinking on leadership and management in order for today's high performing organizations to bridge the strategy-execution gap due to the fact that their strategies translate to specific operational goals.

Keywords: Leadership, Management Strategy, Execution, Municipalities

\section{Introduction}

Strategic leadership is widely identified as an important key driver of strategy execution. However, the lack of strategic leadership is also one of the key barriers preventing successful execution (Beer \& Eisenstat, 2000: 29; Kaplan \& Norton 2004: 277; Hrebiniak, 2005: 17).

Hitt et al. (2007: 375) defines strategic leadership as "the leader's ability to anticipate, envision, to maintain flexibility and to empower others to create strategic change as necessary".

The single most important requirement for organizational success is the ownership and active involvement of the executive team (Kaplan \& Norton, 2001: 3; Hanley, 2007: 19). Leadership must he execution biased, must drive the organization towards successful execution and it must motivate ownership of and commitment to the execution process (Hrebiniak, 2005: 25; Hitt et al., 2007: 53).

Bossidy et al., (2002: 24) argues that an organization can only execute the strategy if the leader's heart and soul are immersed in the organization. The leader has to be engaged personally and deeply in the business. Execution requires a comprehensive understanding of a business, its people, and its environment. The leader must be in charge of getting things done by running the three core processes - picking other leaders, setting the strategic direction, and conducting operations.

\section{Literature Review}

Many managers are not executives, they are superiors of other people and often of a large number of people, and sadly have no impact on the ability of the organization to perform (Drucker, 2004b: 6). 
A key function of management is to recruit and develop talented employees fully aligned with the organization's strategy, setting the course and empowering them as required to carry out their functions. The vision and priorities should be linked to individual and team goals. This will lead to an aligned and motivated organization, which will be able effective in execution (Brenes, 2008: 592).

Culture drives the way the organization implement its strategy. The leader's role is to ensure that the organizational culture enables the execution of the strategy and if it does not, an aligned culture must be build. Once leaders have defined the strategy, they must set their people up for success by ensuring that the culture supports the required behaviours and actions. This is achieved by reviewing current social norms and rituals. If one thing is changed, it does not change the organization. Leaders must examine the day-to-day activities of the organization to ensure it drives strategy execution. (Hrebiniak, 2005: 25; Speculand, 2009: 72-73; Coughlin, 2005: 1; Heide et al., 2002: 219; Kumar, 2010: 323; Bossidy et al., 2002: 30).

Pearce and Robinson (2001: 326) argue that leaders must lead on two fronts: (1) they must embrace change by clarify the strategic direction, build the organization and shape the culture to fit the challenges and opportunities offered by change; and (2) they must provide the management skill to cope with the implications of constant change.

Middle managers play a crucial role in the successful execution of an organization's strategy and should be consulted when strategies and plans are formulated. Without the support and buy-in of the middle management the organization will battle to execute the strategy successfully. It is important that middle managers "are treated like VIPs" and acknowledged when they contribute towards the success of the organization (Antunes et al., 2010: 116 -120).

Speculand (2009: 10-11) is of the view that leaders should focus on five (5) roles as to ensure successful execution of the strategy: (1) focus on both crafting and implementing strategy; (2) create the right conditions; (3) identify what needs to be done; (4) adapt and amend the strategy; and (5) create an implementation plan.

Schaap (2006: 16) stated that in a recent study more than $40 \%$ of senior managers and $90 \%$ of the employees indicated that they do not have a clear understanding of their organization's strategy. Poor communication is one of the main reasons why execution has failed in organizations. Strategy is normally designed at the top, but executed from the bottom.

A strategy that is clear and effectively communicated will not add significant value unless everybody in the organization understand how their actions are strategically aligned and contribute to the strategy execution process. In many cases, strategies are defined at the top of an organization, with no clear cascading of responsibilities for the tactical specifics necessary to achieve results. High-level strategies must be broken down into specific sub-objectives, which can be owned and executed at every level (Hitachi, 2009: 4).

When communicating the strategy and its execution, leaders must be visible throughout the organization and find as many ways as possible to repeat the core messages. When leaders become the voice of the strategy, it demonstrates to the entire organization not only the importance of the strategy but also the focus and commitment of the leadership on its implementation (Speculand, 2009: 42-43; Heide et al., 2002: 218).

Even when the strategy is clearly formulated and defined, it is not always effectively communicated. The study by Jooste and Fourie (2009: 65) found that a lack of understanding and poor communication of the strategy to the workforce is the most important barriers to effective execution. The creation of a common strategy language and communicating it at every level of the organization are almost as important as formulating the strategy itself (Hitachi, 2009:3).

Speculand (2009: 54-55) argues that executing strategy successfully means changing the conversations in the organization. It is estimated that in a weekly management meeting, the team spends 85 percent of its time discussing operations and only 15 percent on strategy and implementation. To be successful in strategy execution strategy this must be reversed.

Kaplan and Norton (2001: 319; 2006a: 2; 2007: 156 \& 160) are of the view that the leadership in the organization must ensure that meetings deal with the important matters defined in the strategy. The role of effective meetings must not be under estimated as an important element in the successful achievement of the organization's strategy. Meetings must be seen as open and team-based learning processes.

It is evident from the literature review that leaders must be engaged and should lead the execution process from the front. The effective and simplified communication of the strategy is as important as strategy itself. Managers should be "executors" instead of supervisors and should create a culture of sticking to due dates. Management meetings should primarily be used to track and monitor the progress of the execution process and the responsibilities of the role-players must be clear and well understood.

The 8 ' $S$ ' strategy execution framework developed by Higgins (2005), is based on the McKinsey Seven 'S' S Framework, first introduced in 1980 by Thomas J. Peters and Robert H. Waterman, Jr. as discussed above. 
Higgins (2005: 4 -6) retained six (6) components of the original McKinsey Framework which are (1) "Strategy and Purpose"; (2) "Structure"; (3) "Systems and Processes"; (4) "Style"; (5) "Staff"; and (6) "Shared Values".

The original "Skills" component was converted into (7) "reSources". Higgins (2005: 4) points out that successful strategy execution is not possible without the allocation and utilization of resources ("reSources") such as money, technology, information and the time required from top management and other role players in the organization. The 8th 'S', "Strategic Performance" was added to provide focus and closure to the execution process and could be used. The seven (7) contextual 'S's should all be aligned and point in the same direction as to achieve "Strategic Performance" as explained by figure 1 (Higgins, 2005: 6).

Figure 1: The Higgins 8 'S' Framework (Aligned 8 'S's)

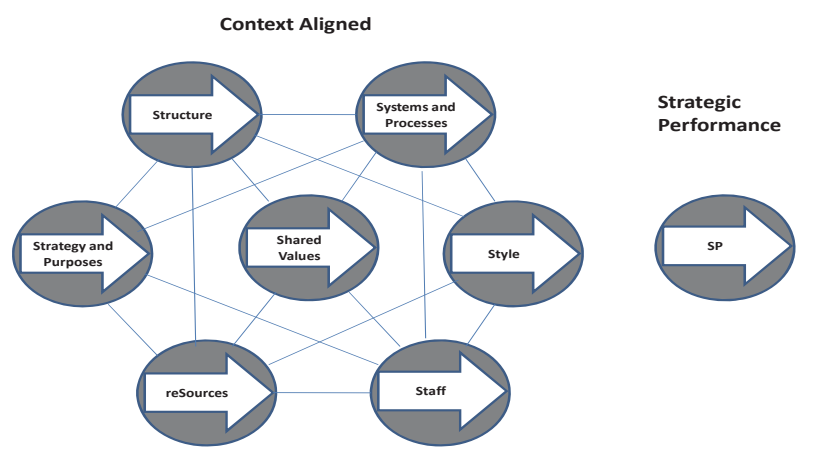

The reality however is that most organizations find themselves in a situation similar to figure 2 where the eight ' $\mathrm{S}$ 's are not aligned and where the arrows points in different directions (Higgins, 2005: 6).

Figure 2: The Higgins 8 'S' Framework (Non-aligned 8 'S's)

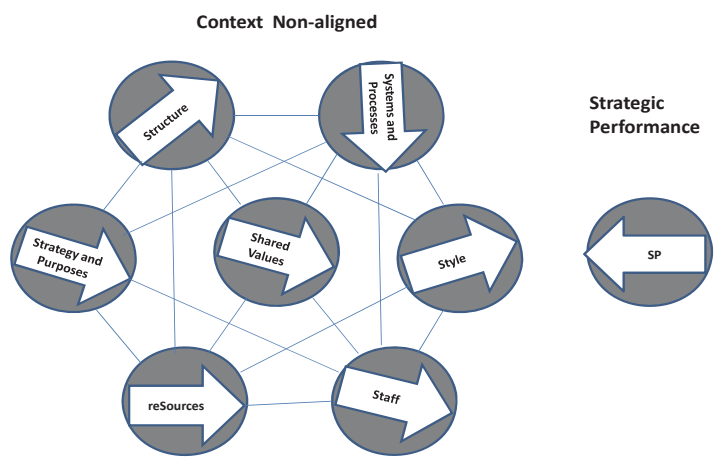

The underlying principle of the '8's Strategy Execution Framework is that different strategies require different systems, shared values, structures, staffing and resources to ensure success (Higgins, 2005: 5).

The Higgins framework is based on and very similar to the McKinsey 7 ' $S$ ' framework. This re-affirms the fact that the McKinsey framework developed by Tom Peters and Robert Waterman is still relevant. Higgins added value to the Higgins framework by adding the very important component of resource allocation and utilization ("resources"). The Higgins framework also added "strategic performance" which ensures focus and an outcome based approach to the strategy execution process. In the case of municipalities the "strategic performance" will be measured in terms customer (community) satisfaction and effective service delivery. The alignment of the various components is an important element 
that was added to the execution process.

\section{Problem Investigated}

The inability to execute strategies is one of the main problems in local government (SA, 2009: 4) and is unfortunately still not receiving the urgent attention it requires. Execution is a discipline on its own which represents a process of interrelated activities which enables an organization to successfully execute strategy. An organization will, in the absence of a well formulated execution plan, not achieve the expected strategic outcomes. (Hrebiniak, 2005: 3).

An excellent strategy may put a municipality or business on the competitive map but only successful execution will keep it there. Most organizations are not doing well when it comes to execution and in many instances it is due to the fact that they over-rely on organizational restructuring instead of focusing on executing the strategy. (Nielson, 2008: 4).

\section{Research Objectives}

\subsection{Research Objective 1}

To review the literature and determine the key factors required for successful strategy execution.

\subsection{Research Objective 2}

To analyze the findings of the empirical study and make recommendations of how to improve the strategy execution process within municipalities by focusing on leadership and management.

\section{Research Methodology}

\subsection{Structured Questionnaire}

A quantitative research approach was utilized and a structured questionnaire with closed questions was chosen as the preferred tool and method to arrive at the expected results.

The purpose of the questionnaire was to establish the municipality's current state and ability to execute strategies. "Strategy Execution" in this questionnaire refers to the execution or implementation of strategies, plans and policies of the municipality. The questionnaire was handed out at the survey sessions. The participants were willing to be honest as their anonymity was assured (Salkind, 2007: 138). The questionnaire posed the questions (statements) on a four-point Likert Scale with a fifth "Don't Know" option. The participants had to consider the following options and respond to each statement:

- "Strongly Agree" (1);

- "Somewhat Agree" (2);

- "Somewhat Disagree" (3);

- "Strongly Disagree" (4); and

- "Don't Know" (5).

A factor analysis was used to identify the structure and factors of the enabler leadership and management and through this process the structural validity of the survey was also determined (Pietersen and Maree, 2007: 219). According to Pietersen and Maree (2007: 219) the purpose of a factor analysis is to determine which statements (items) belong together due to the fact that it measures the same factor.

\subsection{Target Population}

The population of this study comprised of all the senior and middle managers in the Metropolitan, District and Local Municipalities and within the Gauteng Province:

The targeted population consisted of those senior and middle managers responsible for strategy formulation and planning, execution and service delivery as well as two union leaders (shop stewards) representing the two largest unions per municipality. The target population comprised of 351 targeted participants. 


\subsection{Sampling}

To ensure sample adequacy it was decided to use the entire target population as the study sample. All Metropolitan, District and Local Municipalities and the targeted role players within the Gauteng Province will thus form part of the survey.

The target population consisted of 412 people. A total of 379 completed questionnaires were collected. The 379 respondents who responded formed the study population

\section{Results}

\subsection{Frequencies and Descriptive Statistics}

The frequency and descriptive statistical results of the "Leadership and Management" enabler are reported in table 1 below.

Table 1: Frequencies and Descriptive Statistics (Part 1)

\begin{tabular}{|c|c|c|c|c|c|c|c|c|c|}
\hline \multirow[t]{2}{*}{$\begin{array}{l}\text { Statement } \\
\text { Q3.1 }\end{array}$} & \multirow[t]{2}{*}{ Leadership and Management Statements (Part 1) } & 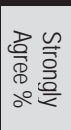 & 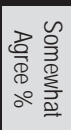 & 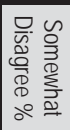 & 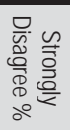 & 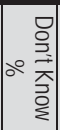 & 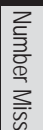 & $\begin{array}{l}3 \\
\mathbb{1} \\
\stackrel{3}{5}\end{array}$ & 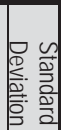 \\
\hline & & 1 & 2 & 3 & 4 & 5 & 焉. & & \\
\hline 1 & $\begin{array}{l}\text { The execution of decisions taken at meetings is monitored at the next scheduled } \\
\text { meeting. }\end{array}$ & 42.5 & 33.5 & 12.1 & 8.4 & 3.4 & 0 & 1.86 & 0.95 \\
\hline 2 & Middle managers have the ability to execute the strategy. & 27.7 & 41.2 & 17.4 & 10.8 & 2.9 & 0 & 2.12 & 0.95 \\
\hline 3 & External stakeholders are engaged on at least a quarterly basis. & 20.6 & 30.3 & 24.8 & 13.2 & 11.1 & 0 & 2.34 & 0.99 \\
\hline 48 & Fraud and corruption is a stumbling block in the effective execution of the strategy & 27.4 & 26.4 & 21.4 & 16.4 & 8.4 & 0 & 2.29 & 1.08 \\
\hline 5 & $\begin{array}{l}\text { During committee meetings of Council (Mayoral, Portfolio and management) - } \\
\text { more than } 50 \% \text { of the allocated time is dedicated at monitoring strategy execution. }\end{array}$ & 10.3 & 29.4 & 21.7 & 19.3 & 19.3 & 1 & 2.62 & 0.99 \\
\hline $6 \circledast$ & Senior management is not involved in the execution of the strategy. & 2.9 & 16.1 & 24.0 & 50.9 & 6.1 & 0 & 3.31 & 0.86 \\
\hline 7 & $\begin{array}{l}\text { Managers at all levels have a clear understanding of what the municipality's } \\
\text { strategic objectives are. }\end{array}$ & 28.5 & 34.3 & 23.0 & 11.9 & 2.4 & 0 & 2.19 & 0.99 \\
\hline 8 & The municipality's strategy is clearly communicated with all employees. & 18.5 & 28.5 & 30.6 & 20.3 & 2.1 & 0 & 2.54 & 1.02 \\
\hline 9 & Senior managers are focusing their time primarily on the execution of the strategy. & 16.6 & 37.2 & 26.9 & 15.6 & 3.7 & 0 & 2.43 & 0.96 \\
\hline 10 & Actions required to ensure successful strategy execution are clearly spelled out. & 19.3 & 35.4 & 27.2 & 15.6 & 2.6 & 0 & 2.40 & 0.98 \\
\hline 11 & Management meetings are well planned. & 30.6 & 32.5 & 19.3 & 15.6 & 2.1 & 0 & 2.20 & 1.05 \\
\hline 12 & Management meetings are productive. & 22.4 & 33.2 & 23.5 & 17.4 & 3.4 & 0 & 2.37 & 1.03 \\
\hline
\end{tabular}

\begin{tabular}{|c|c|c|c|c|c|c|c|c|c|}
\hline \multirow[t]{2}{*}{$\begin{array}{c}\text { Statement } \\
\text { Q3.1 }\end{array}$} & \multirow[t]{2}{*}{ Leadership and Management Statements (Part 1) } & 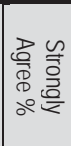 & 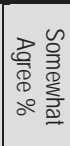 & 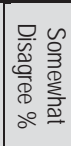 & 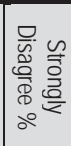 & 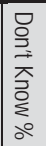 & \multirow[t]{2}{*}{ 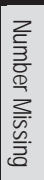 } & \multirow[t]{2}{*}{ 蛋 } & \multirow[t]{2}{*}{ 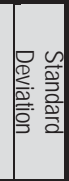 } \\
\hline & & 1 & 2 & 3 & 4 & 5 & & & \\
\hline 13 & Middle managers are committed to strategy execution. & 20.3 & 40.4 & 22.7 & 12.1 & 4.5 & 0 & 2.28 & 0.94 \\
\hline $14 \AA$ & Inadequate delegated powers in the municipality hamper effective strategy execution. & 38.3 & 26.9 & 15.6 & 16.1 & 3.2 & 0 & 2.10 & 1.10 \\
\hline $15 \AA$ & Inadequate management skills in the municipality hamper effective strategy execution. & 30.6 & 40.4 & 14.2 & 12.4 & 2.4 & 0 & 2.09 & 0.98 \\
\hline $16 \AA$ & Coordination across departments and/or municipal entities is poor. & 35.4 & 36.4 & 15.8 & 10.8 & 1.6 & 0 & 2.02 & 0.98 \\
\hline $17 \AA$ & The municipality focuses more on compliance than on execution. & 25.6 & 38.8 & 21.4 & 12.1 & 2.1 & 0 & 2.20 & 0.97 \\
\hline 18 & There are adequate financial resources to accomplish the strategy. & 10.8 & 21.6 & 20.1 & 43.3 & 4.2 & 0 & 3.00 & 1.06 \\
\hline 19 & The managers in the municipality are effective in taking decisions. & 13.5 & 34.3 & 31.1 & 19.8 & 1.3 & 0 & 2.58 & 0.96 \\
\hline 20 & Senior managers set an example of disciplined strategy execution. & 15.0 & 35.4 & 29.0 & 18.2 & 2.4 & 0 & 2.52 & 0.97 \\
\hline 21 & Senior managers set an example of sticking to due dates. & 16.1 & 32.5 & 25.1 & 24.0 & 2.4 & 0 & 2.58 & 1.03 \\
\hline
\end{tabular}

(B) Reversed Statement

Benchmark for each Statement

The benchmark (ideal) in terms of responses for every statement is marked (filled with grey) in the table above. In this section the response benchmark for all the statements is one (1) "Strongly Agree" except for reversed statements 4, 6, $14,15.16$ and 17 where the benchmark is four (4) "Strongly Disagree".

This enabler deals primarily with management's ability to manage and lead the strategy execution process. The respondents are primarily members of the top and middle management which could be a possible limitation but despite 
this, the majority of the statements contained in this factor calculated a mean above 2.5, (or in the case of reversed statements below 2.5), which is an indication that the respondents tended to disagree with some of the statements.

These results support the literature review where it confirms the importance of leadership and management and the fact that it could be a barrier in the strategy execution process if it is not one of the strengths of the municipality.

The detail results of the enabler will be discussed as part of the factor analysis.

\subsection{Factor Analysis}

A factor analysis was conducted on the 21 statements of the "Leadership and Management" enabler as to explore_the factorial structure.

The results of the KMO Measure of Sampling Adequacy, P-value of Bartlett's Test of sphericity and the Determinant of Correlation Matrix are reported in table 2 below.

Table 2: KMO, Bartlett's Test and Determinant of Correlation Matrix

\begin{tabular}{|l|c|}
\hline KMO, Bartlett's Test and Determinant of Correlation Matrix & Value \\
\hline Kaiser-Meyer-Olkin Measure of Sampling Adequacy (KMO) & 0.923 \\
\hline P-Value of Bartlett's Test of Sphericity & $<0.001$ \\
\hline Determinant of Correlation Matrix & $3.329 \mathrm{E}-005$ \\
\hline
\end{tabular}

The KMO Measure of Sampling Adequacy measured 0.923 (superb according to Field, 2009: 647) which suggests that the sample size is adequate for factor analysis. The P-value of Bartlett's Test of sphericity returned a value smaller than 0.05 , indicating that correlations between statements were sufficiently large. The Determinant of Correlation Matrix measured $>0.00001$, which indicates that there is not too severe multicollinearity in the data.

After exploring various multifactor solutions, it was decided to use four (4) factors to explain the "Leadership and Management" section. The four (4) factors each had eigenvalues above Kaiser's criterion of 1.0 (Field, 2009: 671) and in combination cumulatively explained a favourable $58.7 \%$ of the variance. The four-factor solution also made theoretical sense. The results of the factor analysis for the "Leadership and Management" enabler are reported in table 3 below.

Table 3: Pattern Matrixa

\begin{tabular}{|c|c|c|c|c|c|}
\hline \multicolumn{6}{|c|}{ Enabler: Leadership and Management } \\
\hline Statement & Factor 1 & Factor 2 & Factor 3 & Factor 4 & \multirow[t]{2}{*}{ Communalities } \\
\hline Q3.1 & General Management & Execution Hampering & Execution Focus & Management Meetings & \\
\hline 21 & .781 & -.050 & .184 & .198 & .712 \\
\hline 20 & .737 & -.123 & .117 & .183 & .724 \\
\hline 19 & .633 & -.122 & -.049 & .062 & .562 \\
\hline 7 & .608 & -.041 & -.292 & -.081 & .588 \\
\hline 8 & .443 & -.037 & -.289 & .080 & .501 \\
\hline 13 & .436 & .050 & -.294 & .173 & .547 \\
\hline 10 & .430 & .014 & -.296 & .258 & .661 \\
\hline 9 & .401 & .092 & -.270 & .255 & .546 \\
\hline 18 & .155 & .001 & -.013 & -.020 & .023 \\
\hline $15 \circledast$ & -.008 & .769 & .044 & .139 & .539 \\
\hline $14 \circledast$ & -.002 & .606 & -.123 & -.055 & .376 \\
\hline $4 \circledast$ & .026 & .525 & .004 & -.033 & .282 \\
\hline $16 \circledast$ & -.216 & .499 & -.068 & -.069 & .389 \\
\hline $17 \AA$ & .006 & .394 & .210 & -.049 & .258 \\
\hline 1 & -.021 & -.022 & .534 & .269 & .481 \\
\hline 2 & .232 & -.102 & .528 & .005 & .514 \\
\hline 3 & .196 & .009 & .477 & .015 & .370 \\
\hline 5 & .184 & -.023 & .388 & .230 & .454 \\
\hline $6 \rrbracket$ & .050 & .201 & .231 & -.206 & .205 \\
\hline 11 & .046 & -.051 & -.032 & .799 & .746 \\
\hline 12 & .168 & -.056 & -.032 & .737 & .785 \\
\hline
\end{tabular}




\begin{tabular}{|l|c|c|c|c|}
\hline \multicolumn{5}{|c|}{ Enabler: Leadership and Management } \\
\hline \multicolumn{1}{|c|}{ Statement Q3.1 } & Factor 1 & Factor 2 & Factor 3 & Factor 4 \\
\cline { 2 - 5 } & General Management & Execution Hampering & Execution Focus & Management Meetings \\
\hline Cronbach's Alpha & 0.884 & 0.716 & 0.772 & 0.877 \\
\hline Factor Mean & 2.51 & $\begin{array}{c}2.87 \\
8\end{array}$ & 2.12 & 2.29 \\
\hline $\begin{array}{l}\text { Factor Standard } \\
\text { Deviation }\end{array}$ & 0.71 & 0.70 & 0.68 & 0.985 \\
\hline
\end{tabular}

All the statements on each factor loaded above 0.3 , except for statements 6 and 18. The enabler mean calculated at 2.54 which an indication that the statements contained in this section of the questionnaire are viewed by the respondents as evenly balanced between positive and negative.

\section{Discussion}

\subsection{Factor One (1): General Management}

Statements 7, 8, 9, 10, 13, 18, 19, 20 and 21 loaded on factor one (1). These statements are related to the "General Management" factor. All statements except 18 have satisfactory factor loadings of above 0.4 on this factor. Statement 18 ("There are adequate financial resources to accomplish the strategy") loaded low at 0.155 and does not load substantially on any other factor but will be retained due to the fact that the statement is very relevant to the factor.

The communalities for all statements are above 0.3 except for statement 18 which is 0.02 .

The factor mean calculated at 2.51 which is an indication that the statements contained in the factor are viewed by the respondents as evenly balanced between agree and disagree. The possible limitation, as indicated earlier, is the fact that the respondents are primarily members of the management team.

According to the item-level results presented in the table above it seems that the respondents tended to agree that all staff levels have a clear understanding of the strategic objectives (mean of 2.19); that the senior managers are focusing their time primarily on strategy execution (mean of 2.43); that the middle managers are committed to strategy execution (mean of 2.28); and that the actions required to ensure successful strategy execution are clearly spelled out (mean of 2.40).

The results however also indicate that the respondents tended to disagree that the managers are effective in taking decisions (mean of 2.58); that senior managers are setting an example of sticking to due dates (mean of 2.58); and that the strategy is clearly communicated with all employees (mean of 2.54), this statement possibly contradicts the result above where it confirmed that the staff at all levels have a clear understanding of the strategic objectives.

The "General Management" factor shows good reliability with a Cronbach's Alpha Coefficient of 0.884 .

\subsection{Factor Two (2): Execution Hampering}

Statements 4, 14, 15, 16 and 17 loaded on factor two (2). These statements are related to the "Execution Hampering" factor. All statements have satisfactory factor loadings of above 0.5 , except for statement 17 which also loaded satisfactorily with a factor loading of above 0.3 on this factor.

The communalities for all the statements are all above 0.3 except for statement 17 which is 0.26 .

The factor comprises of only reversed statements in the sense that agreement with statements has negative implications for the municipality. The mean calculated at 2.87 an indication that the respondents tended to agree with the statements contained in the factor.

According to the item-level results presented in the table above it seems that the respondents tended to agree that fraud and corruption is a stumbling block in the execution of strategy (mean of 2.29); that the existing delegated powers are inadequate (mean of 2.10); that managerial skills are inadequate (mean of 2.09); that coordination across departments and/or municipal entities is problematic (mean 2.02); and that there is an over emphasis on compliance instead of execution (mean 2.20).

The "Execution Hampering" factor shows good reliability with a Cronbach's Alpha Coefficient of 0.716. 


\subsection{Factor Three (3): Execution Focus}

Statements 1, 2, 3, 5 and 6 loaded on factor three (3). These statements are related to the "Execution Focus" factor. All statements have satisfactory factor loadings of above 0.3 , except statement 6 loaded at 0.23 . Statement 6 (reversed) refers to the involvement of senior management in the execution of the strategy and is relevant and important to the factor according to the literature and will therefore be retained. The communalities for all statements are above 0.3 .

The factor mean calculated at 2.12 which is an indication that the respondents tended to agree with the statements contained in the factor.

According to the item-level results presented in the table above5 it seems that the respondents tended to agree that the execution of decisions taken at meetings is monitored at the next scheduled meeting (mean of 1.86); that middle managers have the ability to execute the strategy (mean of 2.12); that external contractors and stakeholders are engaged on a regular (at least a quarterly) basis (mean of 2.34); and that senior management is involved in the execution of the strategy (reversed statement mean of 3.31).

The respondents tended to disagree with the statement that more than $50 \%$ of the allocated time is dedicated at monitoring strategy execution during committee meetings of Council (mean of 2.62).

The "Execution Focus" factor shows good reliability with a Cronbach's Alpha Coefficient of 0.772.

\subsection{Factor Four (4): Management Meetings}

Statements 11 and 12, loaded on factor four (4). These statements are related to the "Management Meetings" factor. Both statements have satisfactorily factor loadings of above 0.7 on this factor. The communality for statement 11 is above 0.3 and for reversed statement 6 below 0.3 at 0.205 .

The factor mean calculated at 2.29 which is an indication that the respondents, (primarily members of the top and middle management), tended to agree with the statements contained in the factor. According to the item-level results presented in the table above it seems that the respondents tended to agree that management meetings are well planned and productive. This finding contradicts the findings of the factors "General Management" and "Execution Focus" (par. 5.5.2.3). It seems that the content (agenda) of meetings regarding the monitoring of strategy execution requires attention.

The "Management Meetings" factor shows good reliability with a Cronbach's Alpha Coefficient of 0.877.

\subsection{Factor Correlation Matrix}

The Pearson correlations between the extracted factors for the "Leadership and Management" enabler are reported in table 4 below.

Table 4: Factor Correlation Matrixa

\begin{tabular}{|c|l|c|c|c|c|}
\hline \multicolumn{2}{|l|}{ Factors: Leadership and Management } & 1 & 2 & 3 & 4 \\
\hline 1. & General Management & 1.000 & 0.340 & 0.520 & 0.573 \\
\hline 2. & Execution Hampering & 0.340 & 1.000 & 0.212 & 0.401 \\
\hline 3. & Execution Focus & 0.520 & 0.212 & 1.000 & 0.460 \\
\hline 4. & Management Meetings & 0.573 & 0.401 & 0.460 & 1.000 \\
\hline
\end{tabular}

All factors within the "Leadership and Management" enabler had medium to large correlations, except for correlations between the factors "Execution Hampering" and "Management Execution Focus". Although both factors are important enablers of "Leadership and Management", it does not correlate so much with one another.

\subsection{Frequencies: Leadership and Management (Part 2)}

According to the frequencies of "Leadership and Management (Part 2)" in table 5, the respondents tended to agree that to a large extend the minutes of meetings are captured in a project management format $(49.6 \%$ of the respondents responded positively); and that some of the councils utilize a tracking system to monitor the execution of committee resolutions (58.5\% of the respondents responded positively). 
Table 5: Frequencies: Leadership and Management (Part 2)

\begin{tabular}{|c|c|c|c|c|c|}
\hline Statement Q3.2 & Leadership and Management Statements (Part 2) & $\begin{array}{l}\text { } \\
\infty \\
0\end{array}$ & $\begin{array}{l}z \\
\text { zo } \\
0\end{array}$ & 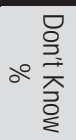 & 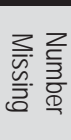 \\
\hline 1 & $\begin{array}{l}\text { Minutes of meetings are captured in project management format (what, } \\
\text { how, when, who, where, etc.). }\end{array}$ & 49.6 & 40.6 & 9.5 & 1 \\
\hline 2 & $\begin{array}{l}\text { A Strategy Execution Team (SET) is established to monitor strategy } \\
\text { execution. }\end{array}$ & 27.2 & 49.6 & 23.3 & 0 \\
\hline 3 & $\begin{array}{l}\text { The strategy execution process incorporates "lessons learned" from the } \\
\text { previous financial year. }\end{array}$ & 32.9 & 45.9 & 21.2 & 2 \\
\hline 4 & $\begin{array}{l}\text { A tracking system monitors the execution of all committee resolutions of } \\
\text { the council (Management, Audit, Risk, Portfolios, MPAC, Mayoral } \\
\text { Committee, Council, etc). }\end{array}$ & 58.5 & 25.4 & 16.1 & 1 \\
\hline 5 & Strategy execution is monitored on a weekly basis at corporate level. & 13.5 & 52.5 & 34.0 & 0 \\
\hline 6 & Strategy execution is monitored on a weekly basis at departmental level. & 25.6 & 54.6 & 19.5 & 1 \\
\hline 7 & $\begin{array}{l}\text { The performance of the municipality is formally assessed at least } \\
\text { monthly. }\end{array}$ & 40.1 & 41.7 & 18.2 & 0 \\
\hline
\end{tabular}

Benchmark for each Statement

Figure 3: Frequency Results: Leadership and Management (Part 2)

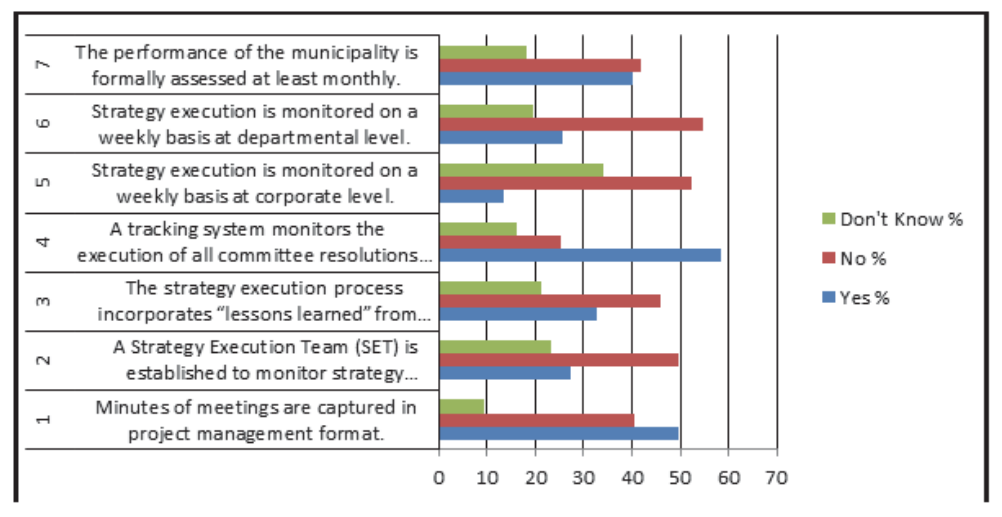

The results also revealed that the respondents tended to disagree that a dedicated strategy execution team (SET) has been established (only 27.2\% responded positively); that the lessons learned from the previous financial year is incorporated into the strategy execution process (only 32.9\% responded positively); that at corporate level strategy execution is monitored on a regular (at least weekly) basis (only 13.5\% responded positively); that at departmental level strategy execution is monitored on a regular (at least weekly) basis (only $25.6 \%$ responded positively).

The respondents were indecisive regarding the statement that performance is regularly (at least monthly) and formally monitored and reviewed.

\subsection{Review of Leadership and Management}

The results supported the findings in the literature review and confirmed the critical role of leadership and management in ensuring successful strategy execution and the fact that it could be a stumbling block in the strategy execution process if it is not one of the strengths of the municipality. The "Leadership and Management" enabler is in the survey explained by four (4) factors: (1)"General Management"; (2) "Execution Hampering"; (3) "Execution Focus"; and (4) "Management Meetings".

Despite the possible limitation that the respondents were primarily members of the top and middle management, the enabler mean calculated at 2.54 which is an indication that the respondents tended to disagree with the statements, 
(or agree with the reversed statements), contained in the "Leadership and Management" enabler.

Areas that require possible attention across the four (4) factors are:

- clear communication of the strategy to all levels of the municipality;

- effectiveness of managers in taking decisions;

- setting an example of sticking to due dates by the senior managers;

- prevention of fraud and corruption;

- inadequate managerial skills and delegated powers;

- coordination across departments and/or municipal entities;

- an over emphasis on compliance instead of execution; and

- the allocation of more time during meetings towards the monitoring of strategy execution.

Part 2 of "Leadership and Management" were only assessed in terms of frequencies and from these results it is evident that the municipalities will have to address the following matters:

- the establishment of a dedicated team to monitor strategy execution;

- the incorporation of lessons learned into the planning and strategy execution process; and

- the regular (at least weekly) review and monitoring of performance and strategy execution at departmental and corporate level

\section{Conclusions}

Leadership and Management calculated a negative mean (above 2.5) The literature confirmed that municipalities in South Africa is well regulated and almost over regulated.

Leadership and Management are important and critical in ensuring successful strategy execution. The actual - and ideal results were reported. According to the empirical results leadership and management is an area that requires attention and this supports the literature.

\section{Recommendations}

Based on the empirical results it is recommended that municipalities consider and implement the corrective measures as proposed. Some of the key leadership and management issues to address are:

- productive meetings focusing on the monitoring and tracking of execution;

- effective decision making and sticking to due dates;

- the prevention of fraud and corruption;

- clear and simplified communication of the strategy;

- improved managerial and project management skills; and

- delegated powers that support effective strategy execution.

\section{References}

Antunes, C., Korda, C., Korda, P. \& Mistry, S. 2010. Leading strategy execution. USA: Kogan Page Limited.

Beer, M. \& Eisenstat, R. A. 2000. The silent killers of strategy Implementation and learning. Sloan Management Review, 41 (4): $29-40$.

Bossidy, L., Charan, R. \& Burck, C. 2002. Execution: The discipline of getting things done. London: Crown Business.

Brenes, E.R., Mena, M. \& Molina, G.E. 2008. Key success factors for strategy implementation in Latin America. Science Direct, 61: 590598.

Coughlin, D. 2005. Strategy, planning and execution: How to establish an effective strategy and execute successfully within it. A Special Report on Business Acceleration.

Drucker, P. F. 2004b. The effective executive: The definitive guide to getting the right things done. New York: HarperCollins.

Field, A. 2009. Discovering statistics using SPSS. 3rd edition. London: Sage Publication.

Hanley, C.A. 2007. The execution challenge: Translating strategy into action. Bank accounting and finance, 17-20, Oct-Nov.

Heide, M., Grønhaug, K., \& Johannessen, S. 2002. Exploring barriers to the successful implementation of a formulated strategy. Scandinavian Journal of Management, 18: 217.231.

Higgins, J.M. (2005). The eight 's's of successful strategy execution. Journal of Change Management, 5(1): 3-13, Mar.

Hitt, M.A., Ireland, R.D. \& Hoskisson, R.E. 2007. Strategic management: Competitiveness and globalization, $7^{\text {th }}$ edition. Ohio: Thompson/South Western.

Hrebiniak, L.G. 2005. Making strategy work: Leading effective execution and change. Upper saddle River, NJ: Wharton School Publishing. 
Jooste, C. \& Fourie, B. 2009. The role of strategic leadership in effective strategy implementation: Perceptions of South African strategic leaders. South African Business Review, 13 (3): 51-68.

Kaplan, R.S. \& Norton, D.P. 2001. The strategy-focused organization. USA: Harvard Business School Publishing Corporation.

Kumar, D. 2010. Enterprise growth strategy. Surrey: Gower Publishing Limited.

Nielson, G. L., Martin K. L. \& Powers E. 2008. The_secrets to successful strategy execution. Harvard Business Review. 61- 70, Jun.

Pearce, J.A. \& Robinson, R.B. 2011. Strategic management: Formulation, implementation and control. New York:

Mc Graw-Hill//rwin.

Pietersen, J. \& Maree, J.G. 2007. Standardisation of a questionnaire. (In Maree, J.G., ed. First steps in research. Pretoria: Van Schaik. Salkind, J. 2007. Exploring research. 6th ed. Uppersaddle River, N.J.: Pearson.

Schaap, J.I. 2006. Toward strategy implementation success: An empirical study of the role senior - level leaders in the Nevada Gaming Industry. Gaming Research and Review Journal, 10(2): 13-29.

Speculand, R. 2009. Beyond strategy: The leader's role in successful implementation. USA: Jossey-Bass.

South Africa (SA). 2009. Department for Cooperative Governance: State of Local Government in South Africa: Overview Report. Pretoria: State Press. 